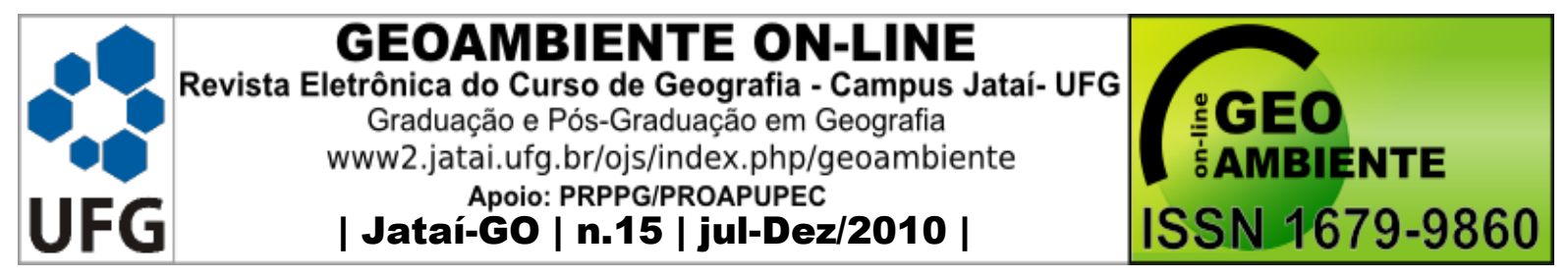

\title{
DESEMPENHO DE CULTIVARES DE ALGODOEIRO HERBÁCEO NAS CONDIÇÕES DE CERRADO EM MINEIROS (GO), SAFRA 2007/08 ${ }^{1}$
}

Lidiane Resende Silva ${ }^{2}$, Marilaine de Sá Fernandes ${ }^{3}$, Ariana Bertola Carnevale ${ }^{4}$ (2 - Faculdades Integradas de Mineiros/FIMES, Egressa do Curso de Agronomia, Rua 22, $\mathrm{s} / \mathrm{n}^{\mathrm{o}}$, Setor Aeroporto, Mineiros/GO, Caixa Postal 104, CEP 75830-000, e-mail: lidiane.rsilva@hotmail.com; 3 - Faculdades Integradas de Mineiros/FIMES, Instituto de Ciências Agrárias, Prof. ${ }^{\text {a }}$ M.Sc. e-mail: marilaine@ fimes.edu.br; 4 - Faculdades Integradas de Mineiros/FIMES, Instituto de Ciências Agrárias, Prof. ${ }^{a}$ M.Sc. e-mail: ariana@ @imes.edu.br)

\section{Resumo}

O objetivo deste estudo foi avaliar o desempenho de cultivares do algodoeiro herbáceo nas condições de Cerrado em Mineiros (GO), na safra de 2007/08. Mineiros fica a $939 \mathrm{~m}$ de altitude e localizado no sudoeste do Estado de Goiás, às margens da rodovia BR-364, a 108 $\mathrm{km}$ a leste do município de Jataí-GO, e a $90 \mathrm{~km}$ a oeste do município de Santa Rita do Araguaia-GO (divisa com o Estado do Mato Grosso), sendo as capitais estaduais mais próximas Goiânia-GO a $420 \mathrm{~km}$ e Cuiabá-MT a $500 \mathrm{~km}$. O experimento foi instalado em parcelas de aproximadamente 1,5 ha. Os tratamentos foram constituídos por quatro cultivares de algodão (Nuopal, DP604BG, Delta Opal e FMT 701), com espaçamento entre linhas de 0,9 metros, 11 plantas por metro linear e densidade de 122 mil plantas por hectare. A característica avaliada foi a produtividade em @ ha ${ }^{-1}$, pesando-se pluma e caroço. Pôde-se verificar que, nas condições em que as quatro cultivares de algodoeiro foram avaliadas, todas apresentaram um bom desempenho para a característica produtividade (@ ha ${ }^{-1}$ ). Apesar de não ter sido detectada diferença significativa, a cultivar FMT 701 apresentou o melhor comportamento, produzindo $299 @$ ha $^{-1}$, seguida pela Nuopal (280@ ha $\left.{ }^{-1}\right)$, Delta Opal (264

Artigo recebido para publicação em 26 de Janeiro de 2010

Artigo aprovado para publicação em 15 de agosto de 2010

${ }^{1}$ Extraído da monografia da primeira autora; 


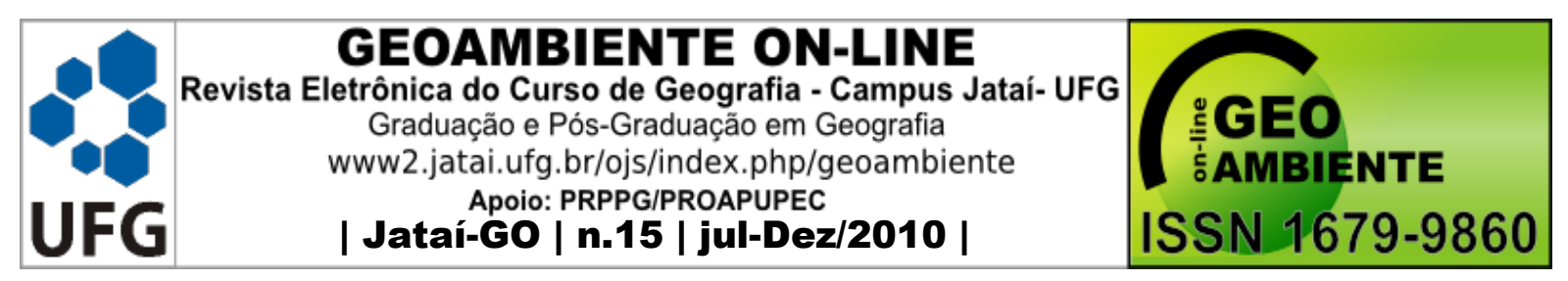

@ ha $\left.{ }^{-1}\right)$ e DP604BG (262 @ ha $\left.{ }^{-1}\right)$.

Palavras chave: Algodão, Produtividade, Cultivares, Cerrado.

\section{Abstract \\ PERFORMANCE OF UPLAND COTTON CULTIVARS IN THE CERRADO CONDITIONS IN MINEIROS (GO), HARVERST OF 2007/08}

The purpose of this study was to evaluate the performance of upland cotton cultivars in the Cerrado conditions in Mineiros (GO), in the harverst of 2007/08. Mineiros is $939 \mathrm{~m}$ of altitude and located in the Southwest of Goias State, near the highway BR-364, $108 \mathrm{~km}$ east from Jataí-GO county, and $90 \mathrm{~km}$ West from Santa Rita do Araguaia-GO county (border with Mato Grosso State), being the nearest state capital Goiânia-GO 420 km and Cuiabá-MT 500 $\mathrm{km}$. The experiment was instaled in plots of approximately $1.5 \mathrm{ha}$. The treatments were consisted of four cotton cultivars (Nuopal, DP604BG, Delta Opal e FMT 701), with spacing between lines of 0.9 meters, 11 plants per linear meter and density of 122 thousand plants per hectare. The evaluated characteristic was the productivity in @ $\mathrm{ha}^{-1}$, weighing in plume and seed. It could be noticed that, in the conditions under which the four cotton cultivars were evaluated, all of them showed a good performance for the caracteristic productivity (@ ha ${ }^{-1}$ ). Although no significant difference have been noticed, the cultivar FMT 701 showed the best behavior, producing $299 @$ ha $^{-1}$, followed by Nuopal (280@ ha $\left.{ }^{-1}\right)$, Delta Opal (264@ ha ${ }^{-1}$ ) and DP604BG (262@ $\left.\mathrm{ha}^{-1}\right)$.

Key Words: Cotton, Productivity, Cultivars, Cerrado.

\section{Resumen}

\section{RENDIMIENTO DE CULTIVARES DEL ALGODÓN HERBÁCEO EN CONDICIONES DE LA SABANA EN MINEIROS (GO), COSECHA 2007/08}

El objetivo de este estudio fue evaluar el rendimiento de cultivares del algodón herbáceo en las condiciones de la Sabana en Mineiros (GO), cosecha de 2007/08. Mineiros está en una altitud de 939 m está situada en el sudoeste del Estado de Goiás, a las orillas de la carretera BR-364, a los 108 km al este del municipio de Jataí-GO, y a los 90 km al oeste del municipio de Santa Rita do Araguaia-GO (límite con el Estado do Mato Grosso), las capitales más 


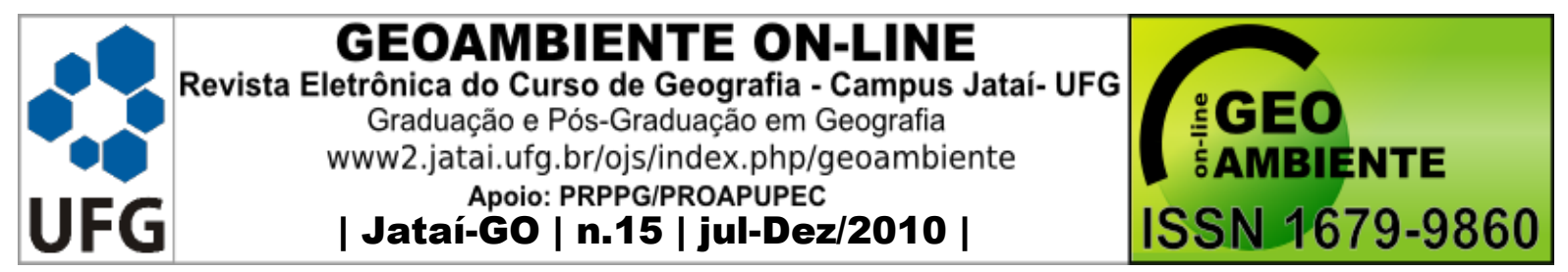

cercanas son Goiânia-GO a 420 km y Cuiabá-MT a 500 km. El experimento se instaló en una porción de terreno de aproximadamente 1,5 ha. Los tratamientos consistieron en cuatro cultivares de algodón (Nuopal, DP604BG, Delta Opal y FMT 701), el espacio entre las líneas fueron de 0,9 metros, teniendo 11 plantas por cada metro linear y con densidad de 122 mil plantas por hectárea. El principal rasgo evaluado fue la productividad en @ ha ${ }^{-1}$, se pesó la pelusa y la semilla. Se comprobó que, en los estados de los cuatros cultivares de algodón evaluados, todos presentaron un desarrollo favorable del rasgo de productividad (@ ha $^{-1}$ ). Aunque no se detectaron ninguna diferencia significativa, el cultivar FMT 701 presentó una mejor performance, con una producción de $299 @ \mathrm{ha}^{-1}$, viniendo sucesivamente como sigue: Nuopal (280@ ha $\left.{ }^{-1}\right)$, Delta Opal (264 @ ha $\left.{ }^{-1}\right)$ y DP604BG (262 @ ha $\left.{ }^{-1}\right)$.

Palabras claves: Algodón, Productividad, Cultivares, Sabana.

\section{1 - Introdução}

O algodoeiro (Gossypium hirsutum L.r. latifolium Hutch) é uma das culturas anuais mais importantes do Brasil, ou seja, um dos produtos de maior importância econômica do grupo das fibras, pelo volume e valor da produção, além da importância social devido ao grande número de empregos gerados direta ou indiretamente (FARIAS, 2005).

Até o início da década de 90 a produção de algodão no Brasil concentrava-se nas regiões Sul, Sudeste e Nordeste. Após esse período, houve um aumento significativo na produção de algodão nas áreas de cerrado, basicamente na região Centro-Oeste. Este fato foi resultante das condições favoráveis para o desenvolvimento da cultura e da utilização de cultivares adaptadas, com arquitetura de planta adequada à colheita mecanizada, alta adaptação às condições edafoclimáticas do cerrado, alta produtividade tanto em caroço quanto em fibra, aliado às modernas técnicas de cultivo (FARIAS, 2005).

Lidar com culturas de ciclo determinado como o milho, o sorgo e a soja é uma tarefa mais simples que manipular culturas de ciclo indeterminado como é o caso do algodoeiro. Esta espécie, apesar de perene, foi domesticada, ao longo dos anos, para ser explorada como cultura anual (AZEVEDO, 2003).

No desenvolvimento de cultivares de algodoeiro para o cultivo em condições de Cerrado são consideradas inúmeras características relacionadas à produção, sanidade e 


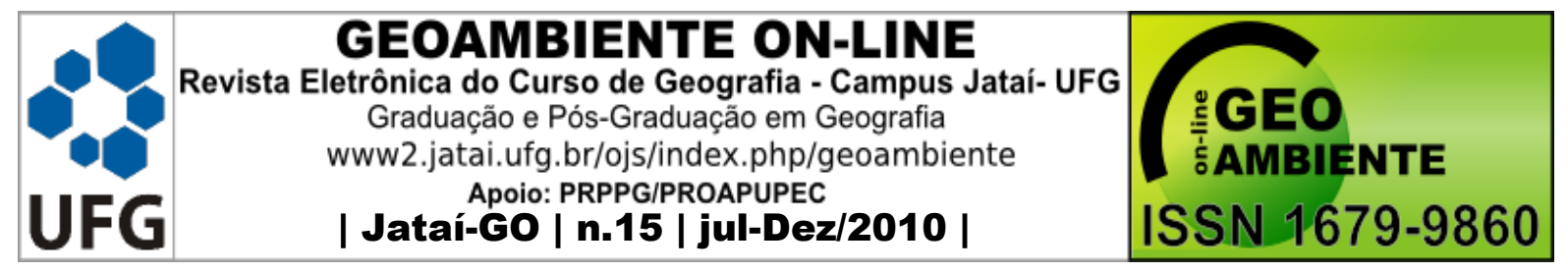

qualidade da fibra, as quais, quando ocorrem harmoniosamente, conferem elevado potencial de uso da cultivar. Entre essas características temos a produtividade potencial superior a 300 @ ha ${ }^{-1}$; resistência à doenças (viroses, ramulose, bacteriose, complexo fusarium + nematóide, alternaria, ramulária e estemphilium); rendimento de fibras superior a $40 \%$; resistência de fibras; finura na faixa de 3,9 a 4,2 (micronaire); fibras de comprimento médio a longo (30 $34 \mathrm{~mm}$ ); ciclo médio (130 a 160 dias); arquitetura favorável à mecanização ao plantio adensado; estabilidade produtiva ao longo dos anos; responsiva à melhoria do ambiente produtivo; resistência ao acamamento; capulhos com boa retenção (MORELLO et al., 2006)

Ainda segundo Morello et al., (2006), o grande desafio é o desenvolvimento de cultivares que manifestem todas essas características mencionadas em níveis ótimos. Ressalta-se que ao longo de anos de pesquisa, com o acúmulo de conhecimento e recursos genéticos, os programas de melhoramento conquistaram significativos ganhos em produtividade de pluma, resistência a doenças e características de qualidade de fibra, porém permanece o desafio de agregar o máximo de características desejadas em um só genótipo.

Assim sendo, o objetivo deste estudo foi avaliar o desempenho de cultivares do algodoeiro herbáceo nas condições de Cerrado em Mineiros (GO), na safra de 2007/08.

\section{2 - Material e métodos}

O trabalho foi desenvolvido em Mineiros, que fica a $939 \mathrm{~m}$ de altitude e localizado no sudoeste do Estado de Goiás, às margens da rodovia BR-364, a 108 km a leste do município de Jataí-GO, e a 90 km a oeste do município de Santa Rita do Araguaia-GO (divisa com o Estado do Mato Grosso), sendo as capitais estaduais mais próximas Goiânia-GO a 420 km e Cuiabá-MT a $500 \mathrm{~km}$.

O experimento foi instalado em parcelas de aproximadamente 1,5 ha. Os tratamentos foram constituídos por quatro cultivares de algodão, com espaçamento entre linhas de 0,9 metros, 11 plantas por metro linear e densidade de 122 mil plantas por hectare.

O preparo do solo foi realizado no sistema convencional onde há inversão da camada arável do solo. Nesse caso foi realizado uma aração profunda, uma gradagem pesada e uma gradagem niveladora para eliminar os excessos de torrões da superfície. Foram realizadas duas dessecações, uns 20 dias antes do plantio e a outra no dia do plantio. 


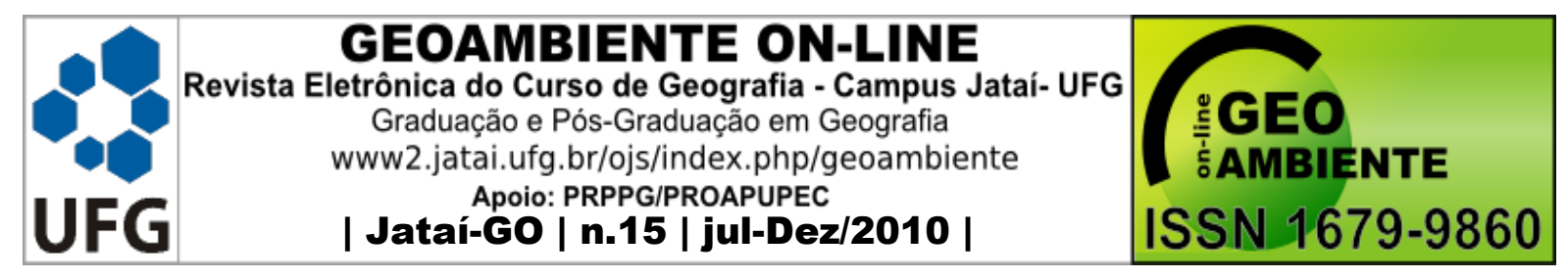

Segundo Andrade (2004) a aração do solo é uma das melhores opções de preparo em relação ao rendimento do algodão.

A adubação foi realizada mediante a interpretação da análise de solo. Um mês antes do plantio foi realizado gessagem utilizando $500 \mathrm{~kg} \mathrm{ha}^{-1}$. No plantio, foi usado $200 \mathrm{~kg} \mathrm{ha}^{-1}$ fosfato monoamônico (MAP), com formulação 12-52-00 (24 kg de N e $104 \mathrm{~kg}$ de P).

A semeadura foi realizada no dia 15/12/2007, tendo como auxílio uma plantadeira. As sementes receberam tratamentos com fungicidas e inseticidas. O espaçamento utilizado entre linhas foi de 0,9 metros e ficaram em torno de 11 plantas por metro linear.

Foram realizadas duas adubações de cobertura. A primeira 20 dias após a semeadura e a segunda 20 dias após a primeira, com $600 \mathrm{~kg}$ de 20-00-20 e 0,4\% de boro.

Foram realizadas 4 aplicações de Nitrato de Potássio (20Kg). A primeira aplicação foi realizada após a emissão da $1^{\mathrm{a}}$ maçã e as outras com intervalos de 15 em 15 dias. Na primeira aplicação, foi utilizado também $200 \mathrm{ml}$ de Base10 (aminoácidos).

Foram realizadas 4 aplicações de regulador de crescimento. O produto utilizado foi o PIX HC sendo este 5 vezes mais concentrado que o PIX normal, pois ele possui $25 \mathrm{mg}$ de Cloreto de Mepiquat.

A primeira aplicação foi realizada a partir do $1^{\circ}$ botão floral e as seguintes aplicações conforme monitoramento, variando de 8 a 15 dias.

Devido o levantamento realizado um mês antes da semeadura, as principais espécies de plantas daninhas encontradas na área, foram: Capim Colchão (Digitaria horizontalis Willd.) e Leiteiro (Euphorbia heterophyla L.).

Além das dessecações foram feitas, uma aplicação de pré-emergente, duas aplicações de pós-emergente, sendo uma para folha larga e outra para folha estreita e uma capina manual antes da colheita.

Dois meses antes do plantio, foram instaladas armadilhas de monitoramento para bicudo (Anthonomus grandis) ao redor da área. A cada 5 ha colocava-se uma. Elas foram numeradas indicando os pontos de entrada das populações de bicudos. $\mathrm{O}$ monitoramento da população de bicudo foi feito semanalmente até o início do florescimento do algodoeiro, após esse período as plantas são mais atrativas que a armadilha. Foram colocadas pastilhas de feromônio para atrair o bicudo do algodoeiro para armadilha. De 


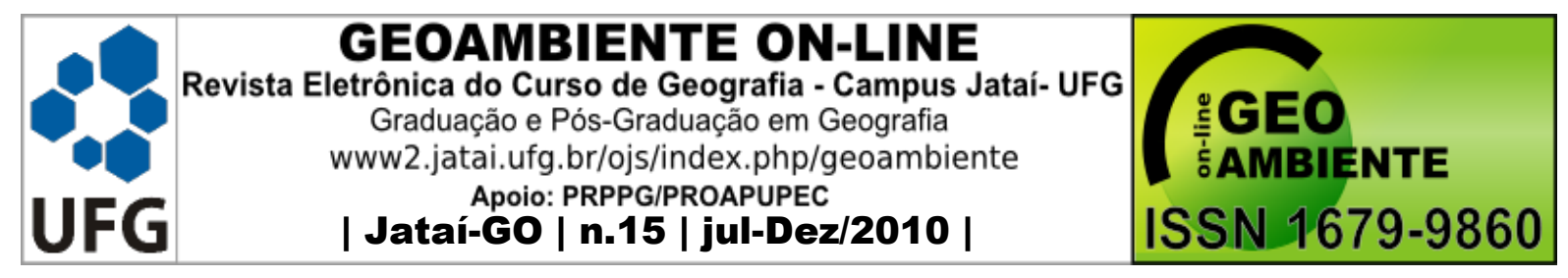

acordo com o Plano Estratégico para Controle de Bicudo da Fundação - Go, a área foi considerada Zona Vermelha, ou seja, foram capturados mais de dois bicudos/armadilha/semana. Portanto, é necessário cercar desde a bordadura, fazendo aplicações nas bordaduras e em área total. Foram realizadas aplicações de bordadura a cada 50 metros, utilizando 1 lt ha ${ }^{-1}$ de Paration Metílico de 5 em 5 dias até o final do ciclo. Em B1 (primeiro botão floral) foram realizadas 3 aplicações específicas para bicudo em área total de 5 em 5 dias conforme recomendação da Fundação - GO (Fundação - Go, 2003).

Foi realizada amostragem de pragas de 3 em 3 dias. Sendo assim, foram amostrados 40 pontos aleatórios e, em cada ponto foram amostrados 5 plantas, totalizando 200 plantas amostradas. De acordo com o índice da amostragem foram realizadas as aplicações de inseticidas, totalizando 8 aplicações de Endosulfan.

Fez-se monitoramento, e à partir da primeira mancha azul (foco da Ramulária) foi feita a primeira aplicação. Após 15-20 dias de intervalo fez-se a segunda e assim sucessivamente até completar 5 aplicações. Não houve incidência de outras doenças, devido várias aplicações para Ramulária.

A colheita foi realizada no dia 23 de julho de 2008, manualmente 218 dias após o plantio. Foram coletadas 4 amostras de 10 metros cada, em pontos aleatórios para cada cultivar.

Para realização do experimento foram selecionadas 4 cultivares, dentre estas se encontram aquelas mais promissoras para a região: Nuopal, DP604BG, Delta Opal e FMT 701.

A característica avaliada foi: produtividade em @ ha ${ }^{-1}$, pesando-se pluma e caroço, com auxílio de balança analítica.

A análise dos dados foi realizada com auxílio do programa estatístico SISVAR (FERREIRA, 2000), realizando-se um teste de comparação de médias.

\section{3 - Resultados e discussão}

Após a aplicação do teste sobre diferença de médias, detectou-se que as médias de produtividade em @ ha $^{-1}$ das quatro cultivares comparadas no estudo, podem ser consideradas iguais ao nível de $5 \%$ de probabilidade. 


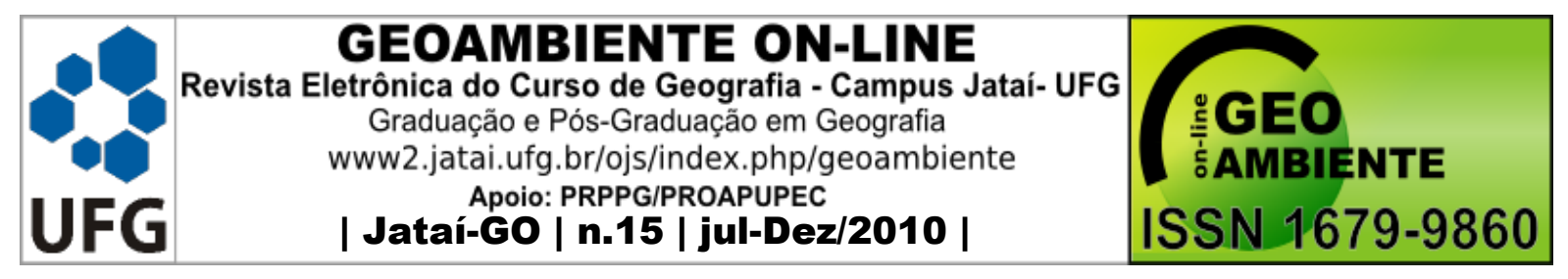

Porém, mesmo não sendo observadas diferenças estatísticas, quando faz-se uma comparação entre os genótipos, a que apresentou a melhor média de produtividade foi a FMT 701 (299 @ ha $\left.{ }^{-1}\right)$ quando comparada com a Nuopal (280@ ha $\left.{ }^{-1}\right)$, DP 604 BG (262@ ha $\left.{ }^{-1}\right)$ e Delta Opal (264 @ ha $\left.{ }^{-1}\right)$ (Tabela 1).

Quando realizada uma comparação levando em consideração que a cultivar FMT 701 apresentou a maior média de produtividade (100\%) observa-se que a cultivar Nuopal apresentou um decréscimo de 6\%. Já a DP 604 BG e Delta Opal, ficaram 12\% abaixo da FMT 701 e $6 \%$ da Nuopal (Tabela 1 ).

Tabela 1: Médias e comparativo em porcentagem de produtividade (@ $\mathrm{ha}^{-1}$ ) do experimento conduzido com a cultura do algodoeiro no município de Mineiros, safra 2007/08.

\begin{tabular}{ccc}
\hline Cultivares & Produtividade $\left(@\right.$ ha $\left.^{-1}\right)$ & Comparativo (\%) \\
\hline Nuopal & 280 & 94 \\
DP604BG & 262 & 88 \\
Delta Opal & 264 & 88 \\
FMT 701 & 299 & 100 \\
\hline
\end{tabular}

Trabalho realizado em Primavera do Leste safra 2005/06 por Lima (2008), mostra que a variedade FMT 701 (239 @ ha ${ }^{-1}$ ) se sobressaiu em relação a cultivar Delta Opal (202 @ ha ${ }^{-1}$ ), mas houve inferioridade quando comparada com as cultivares do presente trabalho que foram de $299 @$ ha $^{-1}$ e $264 @$ ha $^{-1}$.

Martins (2006), realizou um trabalho com diferentes genótipos na região de Mineiros- GO instalado no ICA e neste experimento obteve produtividade média de $293 @$ ha ${ }^{1}$ para a cultivar Delta Opal havendo superioridade em relação ao presente estudo que foi de $264 @$ ha $^{-1}$ para a mesma variedade.

Segundo Aguiar (2005), em experimentos instalados nos municípios de Campo Verde- MT e Pedra Preta- MT ano agrícola 2003/2004, utilizando as mesmas cultivares (FMT 701 e Delta Opal), o mesmo espaçamento (0,90 metros) e a mesma densidade de plantas (122.000) do presente estudo, percebeu-se nos ensaios do município de Campo Verde a média de produtividade das variedades FMT 701 e Delta Opal de 273 @ ha ${ }^{-1}$ e $274 @$ ha $^{-}$ 1 , e quando comparado com as médias de Mineiros-GO a cultivar FMT 701 destacou-se em 


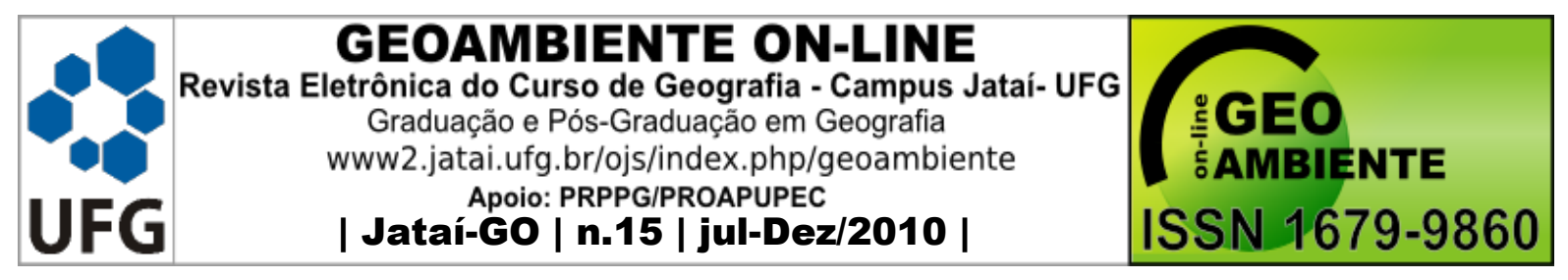

relação a cultivar Delta Opal 35 @ ha ${ }^{-1}$ a mais. Já as avaliações de Pedra Preta apresentam os seguintes resultados, FMT 701 (341@ ha $\left.{ }^{-1}\right)$ e a Delta Opal (305@ ha $\left.{ }^{-1}\right)$ e demonstram superioridade de $41 @$ ha $^{-1}$ e $42 @$ ha $^{-1}$ a mais quando comparadas com o trabalho de Mineiros-GO.

Filho et al., (2008), realizaram experimentos em 23 ambientes do Cerrado brasileiro na safra 2005/06 e concluiram que as variedades FMT 701 e Delta Opal e obtiveram as seguintes médias produtivas, $274 @$ ha $^{-1}$ e $257 @$ ha $^{-1}$. Estes resultados mostram inferioridade quando comparados ao experimento realizado em Mineiros-GO.

Azevedo (2003), realizou um estudo nas condições de Cerrado no município de Paracatu- MG safra 2000/01. A referida região é, hoje, um dos maiores pólos produtores de algodão do Estado de Minas Gerais. O clima da região onde o experimento foi instalado possui as mesmas características do clima do presente trabalho (quente e úmido, com chuvas de verão), temperatura média anual de $24^{\circ}$ e precipitação anual de $750 \mathrm{~mm}$ a $1000 \mathrm{~mm}$, o que significa condições satisfatórias para o cultivo do algodoeiro herbáceo.

O objetivo de Azevedo (2003) foi investigar o desempenho de novas variedades submetidas às condições de Cerrado. Dentre as quatro variedades que foram estudadas pelo autor, a mais produtiva fia a cultivar Delta Opal apresentando média produtiva de 135 @ $\mathrm{ha}^{-1}$, o que não ocorreu no trabalho instalado no Cerrado de Mineiros-GO que obteve uma média de264@ ha $^{-1}$, diferindo um do outro129@ ha ${ }^{-1}$.

Fernandes et al (2007), desenvolveram um experimento realizado no município de Palmas de Monte Alto-BA, a fim de avaliar produtividade em dois diferentes tipos de preparo de solo. Um tipo de preparo é utilizado gradagem pesada e no outro escarificador e dentre as variedades avaliadas por ele encontra-se a Delta Opal. Comparando apenas o uso de gradagem pesada, que foi o mesmo preparo utilizado no trabalho de Mineiros-GO, os autores obtiveram média produtiva da cultivar Delta Opal de 139 @ ha ${ }^{-1}$, inferior a média do presente trabalho que foi de $264 @$ ha $^{-1}$.

O preparo do solo compreende um conjunto de técnicas que quando utilizadas racionalmente, proporcionam incremento na produtividade, mas se mal utilizadas, podem levar a degradação da estrutura dos solos em curto prazo. De maneira geral, as baixas 


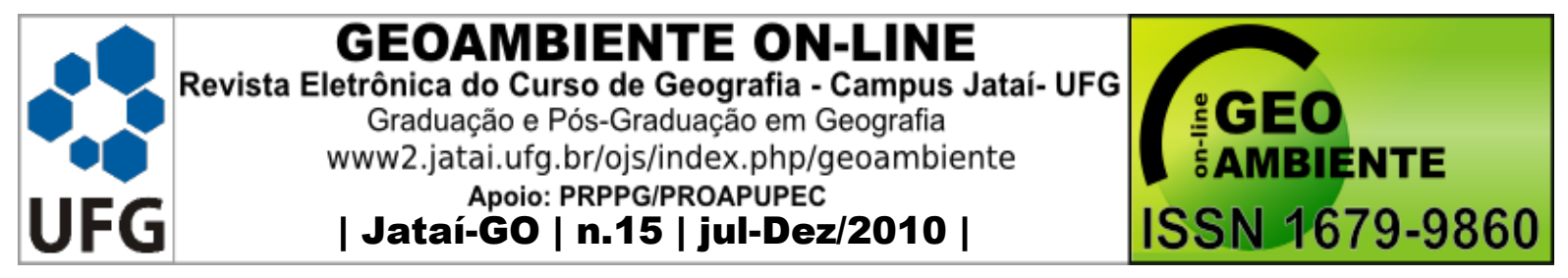

produtividades da cultura são atribuídas, em parte, à degradação dos solos resultante de uso e manejo inadequados e ao preparo do solo insatisfatório (BERTONI \& LOMBARDI NETO, 1990).

Lembra-se que as cultivares em questão são muito exigentes em boa fertilidade do solo. Contudo, no momento da tomada de decisão sobre qual cultivar ser plantada, várias questões devem ser analisadas, pois as cultivares que apresentam maiores produtividades e algum tipo de resistência tende a retornar maiores lucratividades.

\section{4 - Conclusões}

Pôde-se verificar que, nas condições em que as quatro cultivares de algodoeiro foram avaliadas, todas apresentaram um bom desempenho para a característica produtividade (@ $\left.\mathrm{ha}^{-1}\right)$.

Apesar de não ter sido detectada diferença significativa, a ordem decrescente de produtividade entre as quatro cultivares de algodoeiro foi a seguinte: FMT 701 (299@ ha $\left.^{-1}\right)$, Nuopal (280@ ha $\left.{ }^{-1}\right)$, Delta Opal (264@ ha $\left.{ }^{-1}\right)$ e DP604BG (262@ ha $\left.{ }^{-1}\right)$.

\section{5 - Referências bibliográficas}

AGUIAR, P.H.; MELO, J.C, de.; FUJIMOTO, V.R. Avaliação de dois espaçamentos e quatro densidades de planta sobre a produtividade do algodoeiro no Estado de Mato Grosso. CONGRESSO BRASILEIRO DE ALGODÃO- Salvador 2005.

AZEVEDO, D.M.P de. Densidade de Plantio Versus Cultivares de Algodoeiro Herbáceo no Cerrado. Ministério da Agricultura, Pecuária e Abastecimento. Campina Grande-PB. Dezembro, 2003.

BERTONI, J. \& LOMBARDI NETO, F. Conservação do solo. São Paulo, 1990. 355p.

FARIAS, F.J.C. Índice de seleção de cultivares de algodoeiro herbáceo. 121 p. Tese

(Doutorado) - Escola Superior de Agricultura Luiz de Queiroz - Piracicaba, 2005.

FERREIRA, D.F. Sisvar. Lavras - MG, 2000.66 p.

FERNANDES, J.C.; REZENDE, J.O.; REZENDE, V.J.R.P.; VASCONCELOS, O.L. Produtividade de quatro cultivares de algodoeiro submetidos aos preparos de solo convencinal e reduzido, no Vale do IUIU, região Sudoeste da Bahia. Magistra. Cruz das 


\begin{tabular}{|c|c|c|}
\hline & $\begin{array}{c}\text { GEOAMBIENTE ON-LINE } \\
\text { Revista Eletrônica do Curso de Geografia -Campus Jataí- UFG } \\
\text { Graduacão e Pós-Graduacăa em Geografia } \\
\text { www2.jataia.ufg. br/ojs/index.php/geoambiente } \\
\text { Apoio: PRPPG/PROAPUPCC } \\
\text { | Jataí-GO | n.15 | jul-Dez/2010 | }\end{array}$ & $1679-9860$ \\
\hline
\end{tabular}

Almas-BA, v.19, n.3, p.242-249, jul/set., 2007.

FILHO, J.L.S.; MORELLO, C.L.; FARIAS, F.J.C.; LAMAS, F.M.; PEDROSA, M.B.;RIBEIRO,J.L. Comparação de métodos para avaliar a adaptabilidade $e$ estabilidade produtiva em algodoeiro. Pesquisa Agropecuária Brasileira, Brasília, v.43, n.3, p.349-355, mar.2008.

FUNDAÇÃO GO. Medidas de controle do Bicudo do Algodoeiro em Goiás. Folder, 2003.

LIMA, R.S. Levantamento da safra 2005/06 da cultura do algodão. Primavera do Leste, Agência Rural, 09 de out. 2008. Comunicação informal.

MARTINS, B. F., Avaliação de cultivares de algodoeiro no sudoeste do estado de Goiás.

Mineiros: FIMES, 2006 (Monografia de Conclusão do Curso de Agronomia - FIMES).

MORELLO, C.L.; FARIAS, F.J.C.; FILHO, J.L.S.; FREIRE, E.C. Cultivares do Algodoeiro para o Cerrado. EMBRAPA ALGODÂO. Circular Técnica 93. Campina Grande-PB. Agosto, 2006. 